\title{
Geoscience Curriculum Reform Using a Design-Based Approach
}

\author{
Danielle Ford, Education \\ Susan McGeary, Geological Sciences \\ Jennifer Gallo-Fox, Human Development and Family Sciences \\ Cheryl Ackerman, Delaware Environmental Institute
}
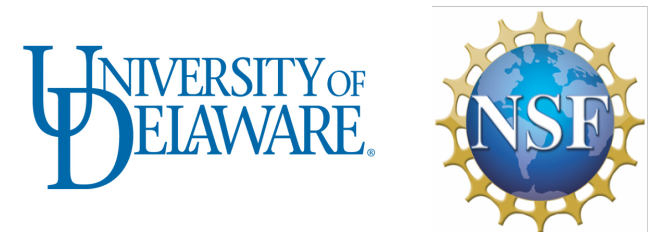


\section{The World in a River Project Goals}

- Redesign large introductory Earth Science course for preservice teachers (PST)

- Elementary and early childhood education majors

- Understand impact of course redesign on PST learning

- On PST content knowledge, self-efficacy for science teaching, and motivation 


\section{Curriculum Reform Principles}

- Align with Next Generation Science Standards (NGSS)

- Field experiences \& active learning

- Place-based investigations \& contextualized content

- Include technological tools and data mining

NRC, 2012a, 2012b. Ausubel, 2000; Deslauriers et al., 2011; DeWitt \& Osborne, 2007; Elkins \& Elkins, 2007; Kern \& Carpenter, 1986; Orion \& Hofstein, 1994; NRC, 2000, 2005, 2007. Apple et al., 2014; Endreny, 2010; Semken \& ButlerFreeman, 2008. Gill et al., 2014; Sinha et al., 2010. 


\section{Content Redesign - Watershed Story}

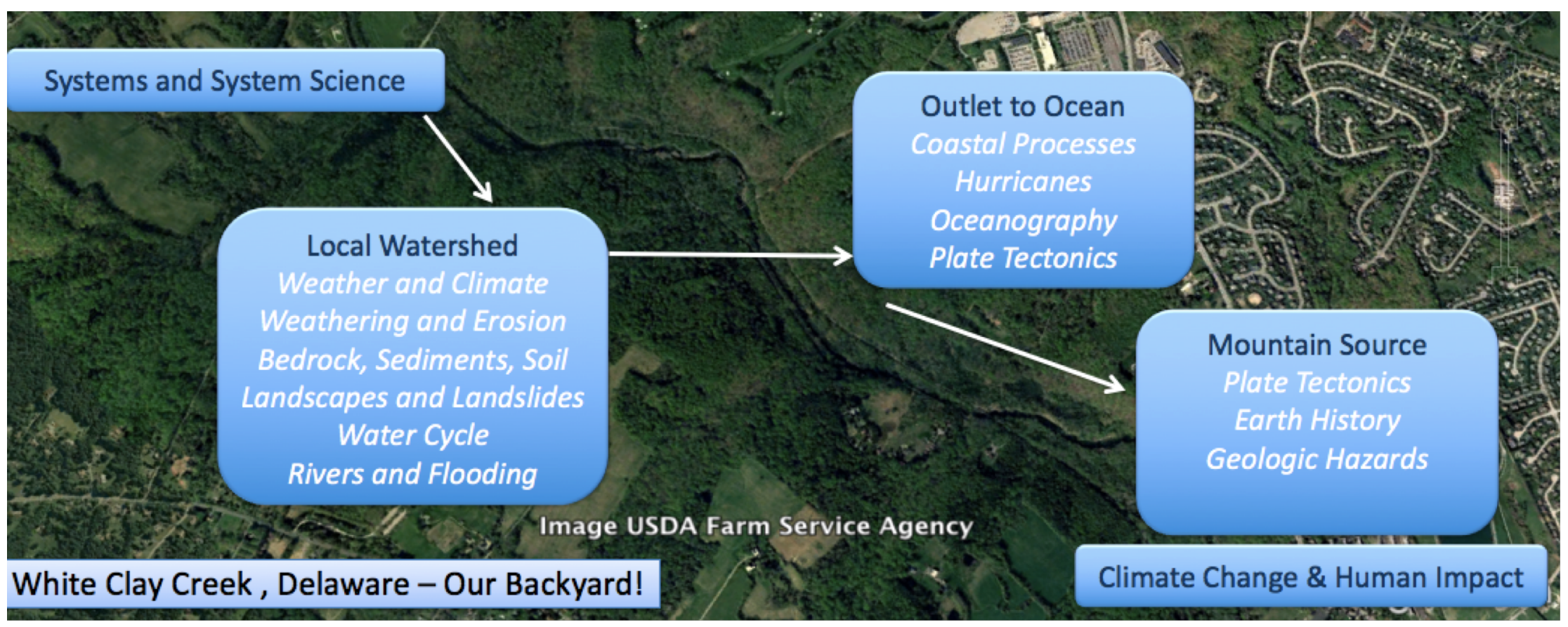




\section{Emphasis on Active, Place-based Learning and Real-time Data, Aligned with the NGSS}

\begin{tabular}{|c|c|c|}
\hline Project & NGSS SEPS & NGSS PEs \\
\hline $\begin{array}{l}\text { Group } \\
\text { Watershed } \\
\text { Research } \\
\text { Project }\end{array}$ & $\begin{array}{l}\text { Students designed and conducted an } \\
\text { experiment out in the watershed. They } \\
\text { started by asking questions (1) to develop } \\
\text { a hypothesis. They planned (3) their field } \\
\text { investigation and then collected, analyzed, } \\
\text { and interpreted the data (4). They } \\
\text { constructed explanations (6) and } \\
\text { communicated (8) in both a group } \\
\text { presentation and individual papers. }\end{array}$ & $\begin{array}{l}\text { PE 4-ESS2-1. Make observations } \\
\text { and/or measurements to provide } \\
\text { evidence of the effects of } \\
\text { weathering or the rate of erosion } \\
\text { by water, ice, wind, or vegetation. }\end{array}$ \\
\hline
\end{tabular}




\section{Research \& Evaluation Principles}

- Design-based approach

- Iterative, responsive relationship between curriculum design and research development over multiple cycles of design, enactment, and reflection

- Quasi-experimental evaluation

- Comparison of traditional and experimental courses using validated measures and observational tools 


\section{Design Based Approaches to Curriculum Reform}

Classroom based, simultaneous integration of the designing of innovative educational environments and experimental studies of these innovations (Brown, 1992)

- Laboratory study findings alone limited in the ability to explain or predict learning in instructional settings

- Classroom based intervention research allows for fine-grained analysis of learning-in-context as well as a site to generate theories

- Engineering approach to design (Collins, 1992) 


\section{DBA Principles}

- Integrating the goals of designing learning environments and developing theories of learning

- Using continuous cycles of design, enactment, analysis, and redesign

- Leading to shareable theories that can be used by both practitioners and other researchers

- Accounting for how design functions in authentic settings

- Relying on methods that appropriately connect aspects of the design with relevant outcomes 


\section{Is DBA a good choice for geoscience education research?}

- Reliable methodological approach with 2+ decades of use

- Preserves values of contextual, situated educational research

- Most DB research comes from STEM educational research (science, mathematics, technology, learning sciences) 


\section{Project Timeline}

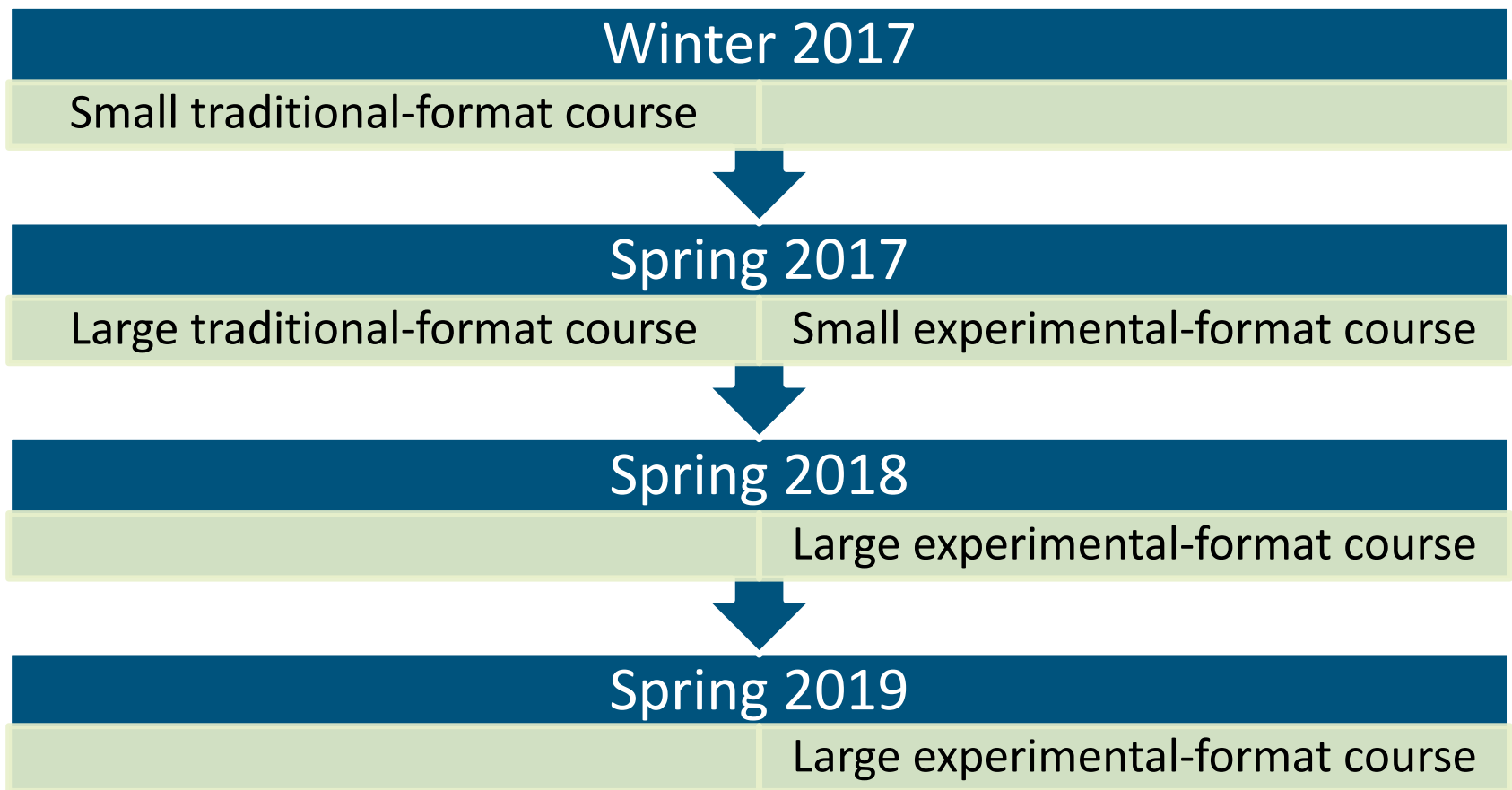




\section{Measures}

\begin{tabular}{|l|l|l|}
\hline Content Knowledge & Geoscience Concept Inventory (GCI) & $\begin{array}{l}\text { Libarkin et al., 2011; } \\
\text { McConnell et al., } \\
2006\end{array}$ \\
\hline Motivation to Learn Science & Science Motivation Questionnaire (SMQ-II) & Glynn et al., 2011 \\
\hline $\begin{array}{l}\text { Self-Efficacy for Science } \\
\text { Teaching }\end{array}$ & Science Teaching Efficacy Beliefs (STEBI-B) & $\begin{array}{l}\text { Enochs \& Riggs, } \\
1990 ; \text { Bleicher, 2004 }\end{array}$ \\
\hline Active Learning & $\begin{array}{l}\text { Classroom Observation Protocol for Undergraduate } \\
\text { STEM (COPUS) }\end{array}$ & Smith et al., 2013 \\
\hline NGSS Practices & NGSS Practice Observation Protocol & Gallo-Fox et al. \\
\hline
\end{tabular}




\section{Findings}

- No pre-post or cross-group changes in motivation, selfefficacy (STEBI-B, SMQ-II)

- Significant pre-post changes in content knowledge, though no group differences (GCl)

- Student and instructor activities shift to active learning; more NGSS practices observed (COPUS, NGSS ) 


\section{DB Research Focus}

\begin{tabular}{l|l|l|}
\hline Design & Conjecture & Analysis \\
\hline $\begin{array}{l}\text { S17 Pilot } \\
\text { - all dimensions of active } \\
\text { learning and reform }\end{array}$ & $\begin{array}{l}\text { Experiencing active } \\
\text { learning will increase PST } \\
\text { learning along 3 } \\
\text { dimensions of NGSS }\end{array}$ & $\begin{array}{l}\text {-No change in learning, but } \\
\text { change in activity } \\
\text {-Note that Watershed } \\
\text { Project is key event (NGSS) }\end{array}$ \\
\hline $\begin{array}{l}\text { S18 } \\
\text { - scale up to large lecture } \\
\text { format }\end{array}$ & $\begin{array}{l}\text { Focus on discipline-specific } \\
\text { NGSS will increase PST } \\
\text { learning }\end{array}$ & $\begin{array}{l}\text {-Increase in content } \\
\text { knowledge }\end{array}$ \\
\hline $\begin{array}{l}\text { S19 } \\
\text {-support TA development } \\
\text {-refine observation tool }\end{array}$ & $\begin{array}{l}\text { Focus on discipline-specific } \\
\text { NGSS will increase PST }\end{array}$ & $\begin{array}{l}\text {-Target specific practices } \\
\text { (planning, explanation) }\end{array}$ \\
\hline
\end{tabular}




\section{Where We Are}

- Success in design

- Curriculum content story more coherent, contextualized

Content and activities are NGSS-aligned

- Shift toward active learning, less lecture, more discourse-focused

- Challenge in seeing impact

- No significant changes in motivation, self-efficacy

- Increases in content knowledge, but same across conditions 


\section{Lessons Learned}

- Selective DBA within the larger instructional reform

- Narrowing focus to NGSS Practices helped us find productive contributions to theories of learning

- Tensions between methods within mixed methods study

- Challenge of preserving quasi experimental design within larger DBA 


\section{Lessons Learned}

- DBA takes time

- Challenge to collect, analyze, refine within timeline

- Challenge to get enough cycles into a funding period

- Ultimately a beneficial methodology

- Instruction responsive to research findings

- Challenges researchers to consider what context demands of theory 


\section{World in a River Project Team}

Susan McGeary (PI)

Geological Sciences

Danielle Ford (co-PI)

Education

Jennifer Gallo-Fox (co-PI)

Human Development \& Family Sciences
Cheryl Ackerman (Evaluator)

Delaware Environmental Institute

Lauren Stegeman (Graduate Assistant) Human Development \& Family Sciences 